\title{
Gene Therapy for Cardiovascular Disease
}

\author{
Kate L. Dishart, Lorraine M. Work, Laura Denby, and Andrew H. Baker* \\ BHF Blood Pressure Group, Department of Medicine and Therapeutics, University of Glasgow, \\ Western Infirmary, Glasgow G11 6NT, UK
}

Received 5 June 2002; accepted 19 July 2002

\begin{abstract}
The last decade has seen substantial advances in the development of gene therapy strategies and vector technology for the treatment of a diverse number of diseases, with a view to translating the successes observed in animal models into the clinic. Perhaps the overwhelming drive for the increase in vascular gene transfer studies is the current lack of successful long-term pharmacological treatments for complex cardiovascular diseases. The increase in cardiovascular disease to epidemic proportions has also led many to conclude that drug therapy may have reached a plateau in its efficacy and that gene therapy may represent a realistic solution to a long-term problem. Here, we discuss gene delivery approaches and target diseases.
\end{abstract}

\section{INTRODUCTION}

Gene transfer enables the overexpression of candidate therapeutic genes either locally or systemically. Cardiovascular disease targets under investigation include therapeutic angiogenesis in ischaemic myocardium and limb muscles, treatment of hypertension, vascular bypass graft occlusion, and prevention of postangioplasty restenosis (Table 1). Cardiovascular diseases are diverse and as such have unique traits requiring precise tailoring of gene therapy strategies to a particular disease. Those features which may vary include mode of delivery, type of vector, length of gene expression, and target tissue. Unlike other inherited genetic defects which may require more long-term gene transfer, transient, nonintegrative gene expression has been shown to be sufficient to promote neovascularization in the case of angiogenesis [1]. This may also apply to antiproliferative strategies for the prevention of neointima formation postangioplasty, for the prevention of instent restenosis, or for gene therapy of coronary artery bypass graft failure $[2,3]$. However, complex diseases with substantial polygenic influences such as essential hypertension will require sustained gene overexpression.

\section{STRATEGIES FOR GENE DELIVERY}

The breadth of applications for vascular gene therapy is accompanied by a need to deliver the therapeutic gene(s) to diverse vascular cell types including vascular smooth muscle (SMC), endothelium, myocardium, or tissues that influence lipid metabolism. Vector systems and gene delivery technologies must therefore be developed for individual applications. The four main modes of introducing therapeutic genes into the vasculature are ex vivo gene transfer to vessel segments and gene delivery using cell-based, systemic, and local delivery approaches.

\section{Ex vivo gene therapy}

Where appropriate, ex vivo genetic modification of vascular tissue is preferred as this allows the delivery of therapeutic genes to the target tissue in a safe and efficient manner. This is the method of choice for gene therapy of vein graft failure. During coronary artery bypass surgery $(\mathrm{CABG})$, there is direct access to the vein in the clinical setting, enabling incubation and subsequent transduction with the vector before grafting. In this way, systemic release of the vector is avoided therefore decreasing potential deleterious transgene expression at distal sites. Additionally, the immune system response to the virus is diminished, since at the time of grafting all excess virus has been removed.

\section{Cell-based genetic modification}

Cell-based gene therapy involves the harvesting of cells from patients, ex vivo transduction to express therapeutic genes, and subsequent reimplantation of genetically-modified autologous cells. There have been very few studies of this kind. Perhaps the best example of this approach is the ex vivo approach used by Grossman et al [4] to treat familial hypercholesterolaemia. They transduced hepatocytes with retroviruses expressing a wildtype copy of low density lipoprotein receptor (LDL-R). Upon reimplantation, a reduction in the total cholesterol level from 671 to 608 was observed for one year [4]. Despite the partial success of this approach, there has been little enthusiasm for this cell-based strategy. In a different approach, injured rat carotid arteries were seeded with 
TABLE 1 . Gene therapy strategies for the treatment of cardiovascular diseases.

\begin{tabular}{lll}
\hline Disease & Therapeutic approach & Target \\
\hline Atherosclerosis & Antiatherogenic & LCAT, apoAI, apoE mRNA \\
\hline $\begin{array}{l}\text { Vein graft failure, } \\
\text { ischaemia, thrombosis }\end{array}$ & Diffusable/secreted gene products & $\begin{array}{l}\text { VEGF, FGF, eNOS, antithrombotic } \\
\text { agents, SOD, heme oxygenase }\end{array}$ \\
\hline Vein graft failure & $\begin{array}{l}\text { Inhibitors of smooth muscle cell } \\
\text { migration/proliferation }\end{array}$ & p53, TIMPs, Rb, p21 \\
\hline Thrombosis & Prevention of thrombus formation & TFPI, tPA \\
\hline Restenosis & Suicide genes & Tk \\
\hline Hypertension & Antisense oligonucleotides & Angiotensinogen, AT ${ }_{1}$ receptor, ACE \\
\hline Vein graft failure & Decoys & Soluble VCAM, E2F \\
\hline Hypertension & Reduction in blood pressure & Kallikrein, ANP, eNOS, endothelin \\
\hline
\end{tabular}

SMCs overexpressing the tissue inhibitor of matrix metalloproteinase (TIMP)-1, a significant decrease in neointimal hyperplasia was observed confirming that this technique can be used to exploit a biological effect [5].

\section{Local gene delivery in vivo}

As many target vascular tissues are inaccessible by systemic vector administration, such as the ischaemic myocardium or atherosclerotic coronary arteries, local delivery devices have achieved substantial attention and development as means of delivering vectors in a safe, selective, and efficient manner. Catheter design has rapidly evolved since its first attempts at arterial wall gene transfer [6]. Delivery catheters can be used under X-ray fluoroscopy guidance for gene delivery and by means of a contrast medium, only the lumen of the vessel is visible. Development of this process using magnetic resonance imaging (MRI) will provide valuable information on the vessel wall structure and interactions between genes and atherosclerotic lesions [7]. Another example of localised vascular gene transfer is by the use of stents [8]. Stents are commonly used devices that provide a scaffold structure to hold diseased arteries open. This can be exploited as a medium through which to deliver genes. Although stents have provided an effective treatment for stenotic saphenous aortocoronary bypass grafts, procedure-related complications have been observed in $20 \%$ of cases [9]. A recent study in a pig model demonstrated stable in vivo transgene expression in the vasculature over a 4-week period from a fibronectin-coated stent platform seeded with green fluorescent protein (GFP) transduced autologous SMC [10]. However, adherence of cells to stent surfaces under flow conditions is particularly poor with certain cell types such as endothelial cells [11]. Stents designed with a distal-embolic protection device in conjunction with a covering of therapeutic genes could be used to prevent adverse coronary events. A wide array of mechanical devices for gene delivery have been investigated for local gene therapy and include double balloon, channel balloon, and hydrogel coated catheters, microporous coated stents, microspheres, and nipple catheters (for review see [12]).

\section{Systemic gene delivery}

Following in vivo administration of viral vector systems, liver sequestration predominantly occurs, precluding efficient vascular gene delivery through this route of administration $[13,14]$. Due to the efficient uptake of systemically administered vectors by the liver, cardiovascular gene therapeutic strategies are limited for this mode of delivery due to the inadequacies in vector technology. However, the liver can be used to modify lipid metabolism [15] or as a factory through which to flood the bloodstream with soluble therapeutic proteins. Systemic gene therapy has been explored for the treatment of hypercholesterolaemia and hypertension (for review see [16]). As an example, systemic injection of adenovirus-apoE into the tail vein of atherosclerotic apo $\mathrm{E}^{-/-}$mice caused an immediate fall in plasma cholesterol levels and a sustained reduction in atherosclerosis [15].

\section{VECTORS FOR GENE THERAPY}

\section{Viral vectors}

Successful gene therapy requires the fulfilment of several criteria, namely, the appropriate therapeutic gene and most importantly a suitable vector for delivery and subsequent efficient expression of the transgene. The ideal gene transfer vector should be nonpathogenic, efficiently transduce target cells, and elicit a minimal immunogenic response whilst providing the required time in vivo. At present, no single viral vector fulfils all the criteria for use in cardiovascular gene therapy and the advantages/disadvantages of each are summarised in Table 2. Examples of the therapeutic use of vectors are given in the relevant section describing cardiovascular disease.

The vast majority of gene transfer studies, not just those pertaining to cardiovascular diseases, have focussed 
TABLE 2. Key features of gene therapy viral vectors.

\begin{tabular}{lcccl}
\hline Viral vectors & Integration & $\begin{array}{c}\text { Long-term gene } \\
\text { expression }\end{array}$ & $\begin{array}{l}\text { Immune response } \\
\text { Comments }\end{array}$ \\
\hline Adenovirus & - & - & + & $\begin{array}{l}\text { Broad tropism, easy to produce high titre stocks, } \\
\text { widely characterised in vivo }\end{array}$ \\
\hline $\begin{array}{l}\text { Adeno-associated } \\
\text { virus (AAV) }\end{array}$ & + & + & - & $\begin{array}{l}\text { Limited cloning capacity, nonpathogenic, integrate } \\
\text { randomly in the absence of the rep gene }\end{array}$ \\
\hline $\begin{array}{l}\text { Lentivirus } \\
\text { Retrovirus }\end{array}$ & + & + & - & $\begin{array}{l}\text { Retrovirus-derived, pseudotyping with heterologous } \\
\text { coat proteins improves biosafety }\end{array}$ \\
\hline
\end{tabular}

on the use of adenoviruses. Adenovirus (Ad) is by far the most commonly applied and well characterised of the existing viral vectors from an experimental or clinical standpoint. Indeed, of all ongoing gene therapy clinical trials almost $28 \%$ can be attributed to Ad-based protocols with less than $8 \%$ treating vascular disorders (http://www. co.uk/genmed). Ad-mediated gene therapy is dependent on the level of the coxsackie-adenovirus receptor (CAR) and integrins $\left(\alpha_{\mathrm{v}} \beta_{3}\right.$ and $\left.\alpha_{\mathrm{v}} \beta_{5}\right)$ expressed on the target cell (Figure 1a). In the context of the cardiovascular system, Ad infection levels are relatively low when compared to the hepatic system, however, many successful gene therapy applications have been documented using local delivery to target tissue and clinical trials are ongoing [12]. Ad can be produced to a high titer and will infect both nondividing and dividing cells. However, Ad can result in a marked inflammatory and immunogenic response limiting gene expression, which remains relatively transient but can be overcome with gutless Ad vectors [15].

The last few years have seen an increase in studies with adeno-associated virus (AAV)-based vectors and consequently AAV has emerged as an important vector system for gene therapy. rAAV is a replication-defective virus that is unable to replicate without a helper virus (Figure 1b). It can be stripped of its viral genes to allow a virus coat that can be packaged with a transgene cassette of up to $4.5 \mathrm{kbp}$. Unlike other viral vectors, AAV has the ability to integrate into the genome therefore allowing long-term expression of the transgene, although in nondividing cells it appears that rAAV vectors can exist as high-molecular weight episomal DNA [17]. wtAAV integrates stably into chromosome 19 [18] however, rAAV vectors do not specifically integrate at this site as rep protein is required to produce this site specificity [19]. This problem can be overcome by inserting a truncated rep protein, which allows the rAAV to restore its ability to integrate at the chromosome 19 site [20]. Single intramuscular injection of AAV-LacZ into immunocompetent mice produced detectable expression for more than 1.5 years without any evidence of a cellular immune response [21]. The lack of immunogencity of AAV is an important feature of the vector and gives it a major advantage over adenoviruses (Table 2).

\section{Nonviral vectors}

Of the cardiovascular trials running in 2001, 47\% used either plasmid DNA or liposome carriers [1]. One approach involves the use of synthetic antisense oligonucleotides, designed to attenuate detrimental proteins [22]. Cis-element double-stranded oligodeoxynucleotides (also known as decoys) have been employed to modulate gene expression through the removal of trans-acting factors from endogenous cis-elements [23]. This is not only a powerful gene therapy strategy but also enables the study of endogenous gene regulation both in vitro and in vivo. For the cardiovascular system, ultrasound can enhance gene therapy of naked plasmid DNA and has been shown to increase biological effects of therapeutic genes such as p53 [24]. Gene transfer of recombinant human VEGF cDNA in a rabbit model of arterial balloon injury led to reendothelialization which was $95 \%$ complete within 1 week [25]. In turn, intimal thickening and the occurrence of thrombotic occlusion were diminished with an associated restoration in endothelial cell-dependent vasomotor reactivity. The treatment of peripheral vascular disease has seen the intramuscular injection of plasmid DNA encoding vascular endothelial growth factor (VEGF) to increase collateral vessel development and tissue perfusion in the muscle [26]. Importantly, in a clinical trial using ex vivo E2F decoy oligodeoxynucleotide transfection of human vein grafts, Mann et al [42] have shown this strategy to reduce proliferation and hence the occurrence of vein graft occlusion. In addition, no clinical complications were associated with the procedure.

\section{CARDIOVASCULAR DISEASE TARGETS FOR GENE THERAPY}

Many diseases affecting the cardiovascular system are amenable to gene therapy protocols. Indeed, success has been achieved experimentally. Here, we briefly review the therapeutic strategies relating to the treatment of ischaemia, late vein graft failure, atherosclerosis, thrombosis, and hypertension. 


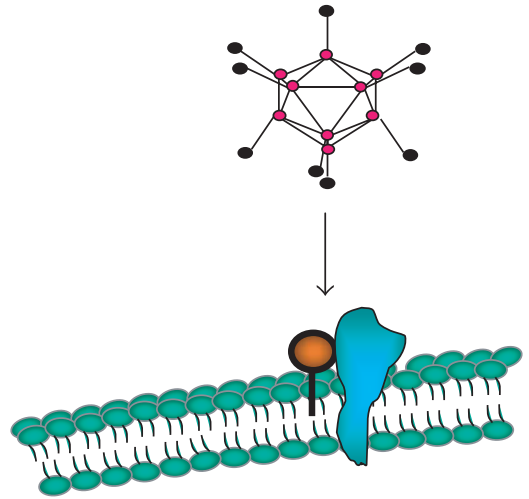

Ad 5

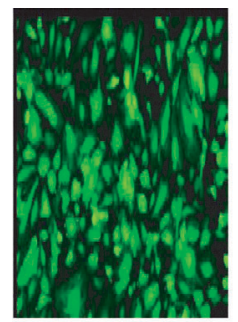

EC

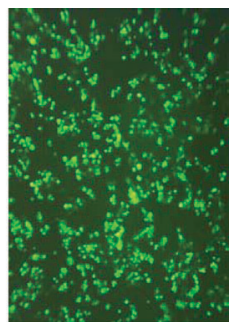

Hepatocytes

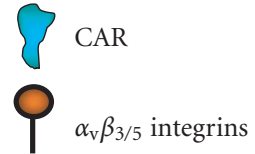

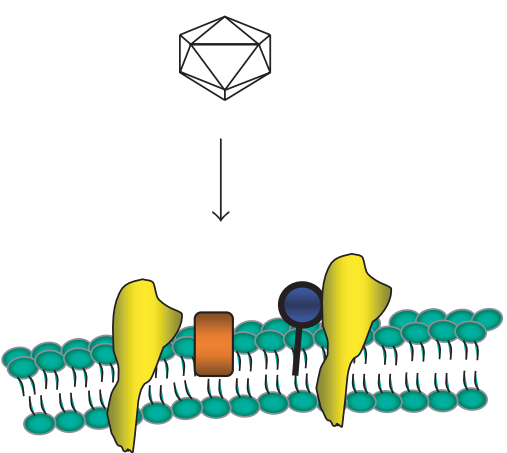

AAV-2

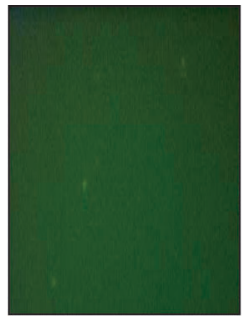

EC

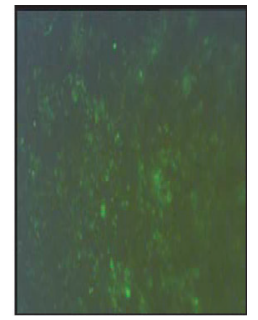

Hela

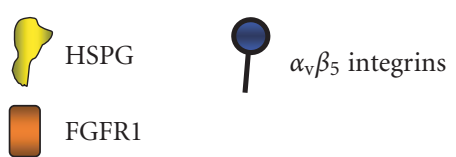

(b)

FIGURE 1. (a) Adenoviral (Ad) attachment and internalisation is mediated through the knob protein of the fiber binding to CAR, followed by interaction of the penton base at the base of the fiber shaft with $\alpha_{\mathrm{v}}$ integrins on the cell surface. Following internalisation, the virus is localised within cellular endosomes which upon acidification allows the virions to escape and traffic to the nucleus. Admediated infection is therefore, dependent on levels of CAR with hepatocytes being highly permissive as shown with reasonable levels of transduction in endothelial cells (EC). (b) AAV2 binds to the primary receptor heparin sulfate proteoglycan (HSPG) on the cell surface and internalization is assisted by the secondary receptors $\alpha_{\mathrm{v}} \beta_{5}$ integrins and fibroblast growth factor receptor 1 . Transduction of vascular cell, in particular EC, is very poor compared with permissive cell types such as HeLa. Transduction of both cell types with rAAV2-eGFP clearly shows the difference in transduction efficiency.

\section{Ischaemia}

Peripheral ischaemic diseases are commonly associated with the lower extremities and can be characterized by an impaired blood supply resulting from narrowed or blocked arteries, which subsequently starve tissues of the necessary nutrients and oxygen. Similarly, inadequate blood flow to the heart gives rise to myocardial ischaemia. This may occur if coronary flow is reduced by the presence of an atherosclerotic plaque, a blood clot or an artery spasm. Surgical bypassing and percutaneous revascularization have alleviated many of the symptoms but is not suitable for all patients due to the extension of arterial occlusion and microcirculation impairment. Amputation and heart transplants are the only forms of treatment for ischaemia and therefore gene therapy provides an alternative solution $[27,28]$. The two main therapeutic genes under investigation are the angiogenic growth factors (VEGF) and fibroblast growth factor (FGF). Research has focused on delivering these agents to the site of ischaemia (Table 1). VEGF is a heparin binding glycoprotein, which is a principal angiogenic factor for endothelial cells. The delivery of VEGF to target cells lends itself to gene transfer since it is naturally secreted from cells and therefore can achieve its biological effect with a limited number of transfected cells (Figure 2). Gowdak et al [29] demonstrated that intramuscular injection of AdVEGF 121 resulted in significant lengthening of arterioles and capillaries of nonischaemic limbs in the rat and rabbit. Furthermore, tissue perfusion in animals receiving gene delivery two weeks prior to experimental induction of skeletal muscle ischaemia by removal of the femoral artery was preserved [29]. Clinically, Admediated transfer of VEGF has been demonstrated to improve the endothelial function and to lower the extremity flow reserve in patients with peripheral arterial disease. In this case, AdVEGF ${ }_{121}$ was delivered intramuscularly 


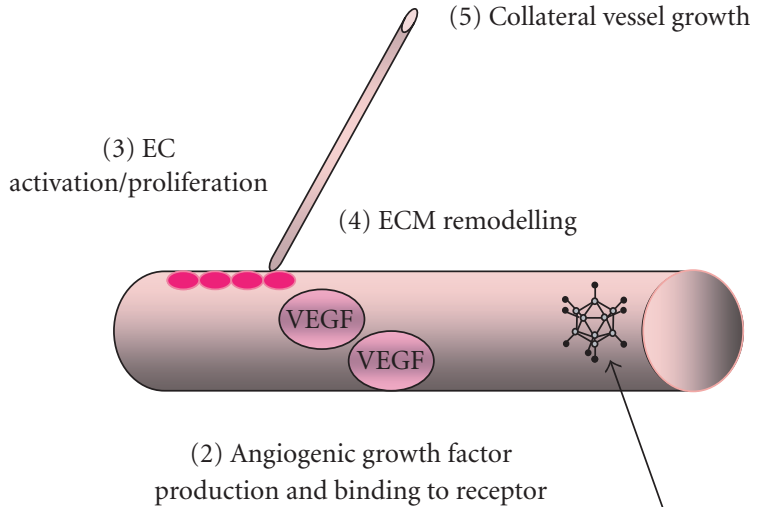

(1) In vivo virus administration

Figure 2. Angiogenesis in the ischaemic myocardium. Diseased or injured tissues produce and release angiogenic growth factors that diffuse into nearby tissues. To boost concentration of these growth factors, such as VEGF, viruses engineered to express one of the 19 existing angiogenic growth factors can be injected into the ischaemic area [1]. The angiogenic growth factors bind to specific receptors located on the endothelial cells (EC) of nearby preexisting blood vessels [2]. Activation of EC by VEGF occurs upon binding to its receptors [3]. Synthesis of new enzymes is triggered. These enzymes dissolve tiny holes in the sheath-like covering (basement membrane) surrounding all existing blood vessels. The endothelial cells proliferate and migrate out through the dissolved holes of the existing vessel [3]. Extracellular matrix (ECM)-degrading enzymes dissolve the tissue in front of the sprouting vessel tip [4]. As the vessel extends, the tissue is remoulded around the vessel and proliferating endothelial cells roll up to form a blood vessel tube [5]. Blood vessel loops are formed from individual blood vessel tubes and these are stabilized by the formation of SMC.

and endothelial function determined 30 days postinjection [30].

In a phase-I clinical trial involving a group of $21 \mathrm{pa}-$ tients given AdVEGF $_{121}$ by direct myocardial injection into the ischaemic region, no adverse effects were detected locally or systemically. Furthermore, angiography suggested an improvement in the area where the vector had been delivered and patients described alleviation in angina symptoms [31]. More recently, the AGENT trial has addressed the safety and anti-ischaemic effects of administering Ad-FGF4 in patients suffering from angina. Single intracoronary infusion of Ad-FGF4 was shown to result in improved exercise times assessed using the exercise treadmill test compared to the placebo group and no adverse side effects [32]. A single intramuscular injection of AAV-VEGF has been shown in the rat ischaemic hindlimb model to produce an increase in capillary growth, a significant increase in mean blood flow of the ischaemic limb, and a higher average skin temperature [33]. An intracardiac injection of AAV-VEGF 165 has also been shown to induce angiogenesis in the ischaemic myocardium without any evidence of angioma formation [34].
Although VEGF has positive effects on the promotion of angiogenesis, there are pertinent safety considerations. It has been shown that VEGF may enhance atherosclerotic plaque development through an increase in focal macrophage levels [35]. Macrophages then induce those growth factors and cytokines, which mediate intimal hyperplasia and contribute to plaque instability through enhancing levels of matrix metalloproteinases (MMPs) and other hydrolytic enzymes. Other potential risks of therapeutic angiogenesis include the production of nonfunctional, leaky vessels, and stimulation of angiogenesis in tumours [36]. Animal studies in mice highlight the need for regulated expression of VEGF as persistent unregulated VEGF expression following intraventricular injection resulted in the formation of intramural vascular tumours at the site of myoblast implantation [37]. The development of tissue-specific vectors and promoters may help to minimise the risks from these adverse reactions.

\section{Protection from reperfusion injury}

Reperfusion of ischaemic myocardium resulting from dissolution of the blockage by clinical intervention, may in turn further injure the damaged tissue as a result of reperfusion injury. Reperfusion leads to oxidative stress in the tissue and hence may itself require intervention. Hypoxic regulatable elements and overexpression of agents, which scavenge free radicals or reduce oxidative stress, have been targeted using gene therapy protocols (Table 1). To produce long-term myocardial protection Melo et al [38] used AAV to deliver the cytoprotective heme oxygenase gene by intramyocardial injection into rat hearts. They found that eight weeks after administration of the AAV-hHO-1 when acute coronary artery ligation was performed the treated rats had a dramatic reduction in myocardial infarction size [38]. Phillips et al [39] also devised a cardioprotective strategy using a "vigilant vector" AAV construct. This involves a heart specific promoter, MLC2v, which only expresses mRNA in the heart. The vector also includes a hypoxia regulatory element (HRE) which can act as an "on" switch so that production of the transgene antisense AT1R only occurs when ischaemia is detected. This would result in long-term protection of cardiac function during bouts of ischaemia [39]. In an acute model of oxidative stress, the effects of expression of superoxide dismutase (SOD) from adenoviral vectors was investigated [40]. High doses of Ad-SOD3 (3 $\left.\times 10^{10} \mathrm{pfu}\right)$ resulted in a 3 -fold elevation of serum SOD activity and was protective against hepatic ischaemia-reperfusion injury.

\section{Late vein graft failure}

As one of the most commonly performed surgical procedure at some 400,000 cases worldwide each year, coronary artery bypass grafts (CABG) are effective at relieving symptoms of angina and prolong life for those patients with multiple vessel disease. Vein grafts are inserted into the arterial circulation and undergo a sequence of 


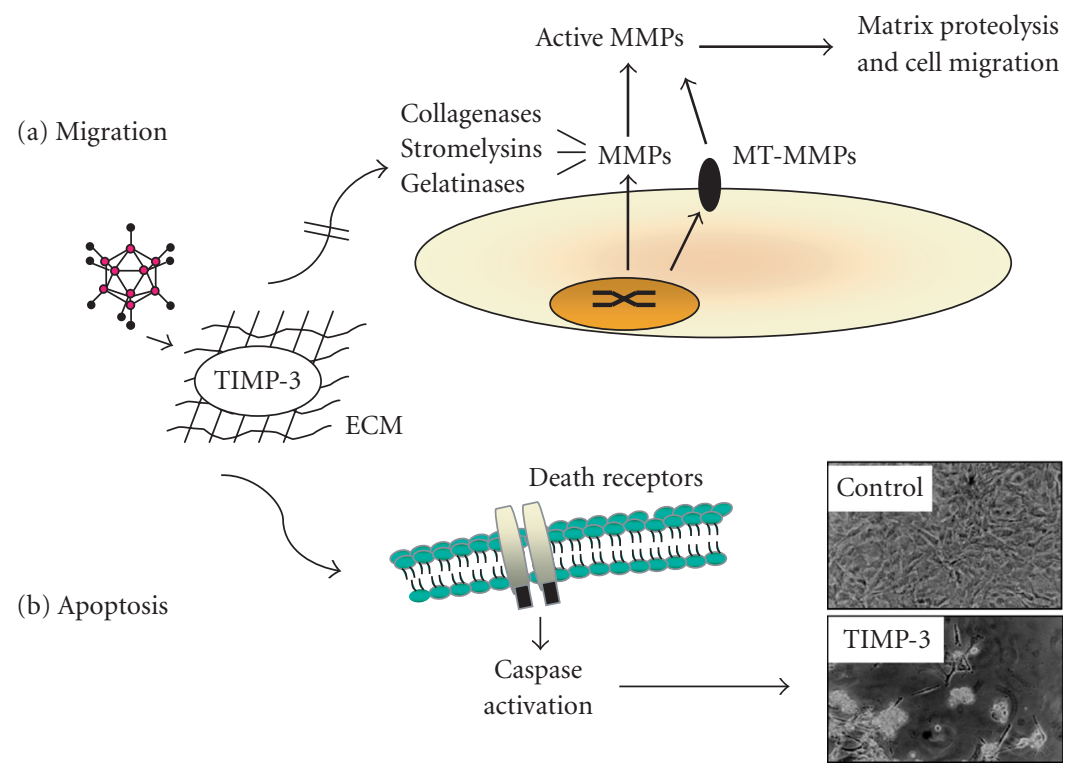

Figure 3. Gene therapy by overexpression of TIMP-3. Following Ad-mediated gene delivery to vascular smooth muscle cells, TIMP-3 is secreted and is found located with the extracellular matrix (ECM). From here, TIMP-3 is available to exert two distinctly different phenotypes through its metalloproteinase inhibitory effects. (a) Matrix metalloproteinases (MMPs, including collagenases, stromelysins, gelatinases, and membrane-type metalloproteinases [MT-MMPs]) are upregulated following vascular injury. TIMPs, through their native MMP inhibitory activity, are able to bind to and retard pro-MMP-to-active enzyme conversion and combined with the ability to block active MMP activity, matrix proteolysis and hence cell migration is inhibited [45]. (b) TIMP-3, uniquely amongst the TIMP family, is also able to promote smooth muscle cell death through death receptor-induced caspase activation and induction of apoptosis [46]. Micrographs courtesy of Mark Bond, Bristol Heart Institute, UK.

adaptive physiological changes. Early thrombotic occlusion occurs in $10 \%$ of grafts with patency rates of $50 \%$ over 10 years due to the onset of intimal thickening and atheromas [3]. Early thrombosis occurs in the first few weeks after grafting, particularly at the distal anastomosis due to vessel wall injury. Drug treatments include aspirin and other antiplatelet agents, which reduce but do not eliminate early occlusions but are often associated with hemorrhagic side effects. Late vein graft failure is characterized by progressive medial thickening and neointima formation. Therefore, vein graft failure limits the clinical success of coronary bypass grafting in terms of symptoms and mortality.

Remodelling of the vascular wall by MMPs promotes SMC migration and proliferation, ultimately leading to neointima formation and a narrowing of the vessel lumen [3]. The main therapeutic targets in the context of late vein graft failure are those affecting SMC migration and proliferation. Vein graft lends itself ideally to gene therapy, as there is a clinical therapeutic window whereby surgically prepared vein can be genetically modified prior to grafting. Many candidate therapeutic target genes have been studied experimentally with the aim to prevent the formation of neointimal lesions associated with late vein graft failure (Table 1). SMC proliferation and migration and matrix degradation are integral to lesion formation and hence, among those classes of gene investigated are antiproliferative, proapoptotic, antiinflammatory, or antimigratory agents (for review see [41]).
The PREVENT clinical trial [42] aimed to assess the efficacy of intraoperative gene therapy in patients receiving bypass vein grafts. By blockading the cell transcription factor E2F with decoy oligodeoxynucleoties at the time of grafting, they were able to significantly reduce the incidence of post-operative occlusion. E2F upregulates up to a dozen cell cycle genes and its inhibition inhibits target cell cycle gene expression and DNA synthesis. The success of this trial in reducing bypass graft failure in a high risk cohort underlines the important role that gene therapy could play in the prevention of vein graft failure.

MMPs have been shown to be an integral part of neointima formation, and overexpression of the naturally occurring tissue inhibitors of MMPs (TIMPs) is a possible approach. Ad-mediated transfer of TIMPs has been demonstrated in a number of models of vein graft failure. In a mouse model, local delivery of Ad-TIMP-2 was found to reduce vein graft diameter [43]. In contrast, using the pig saphenous vein-carotid artery interposition graft model, George et al [46] demonstrated that while Ad-mediated TIMP-2 delivery was ineffective at reducing vein graft neointima formation, TIMP-3 had a profound inhibitory effect on lesion formation (Figure 3). This was attributed, in part, to its proapoptotic effect in the medial and neointimal layers. Encouragingly, the results from the porcine model were translated into a human ex vivo model of vein graft failure with an $84 \%$ reduction in neointima formation following local delivery of Ad-TIMP-3 [46]. Similarly, TIMP-1 was also shown to 
have an inhibitory effect on lesion formation in this model [47].

Endothelial nitric oxide synthase (eNOS) is important to vascular homeostasis and plays a vasoprotective role by inhibiting platelet and leukocyte adhesion, inhibiting SMC proliferation and migration, and in turn promoting endothelial survival. Local eNOS delivery would, in theory, arrest the proliferative response to vascular injury. Nitric oxide (NO) bioactivity is substantially reduced postbypass graft surgery whilst levels of NO scavenging superoxide are increased. It is therefore likely that the loss of NO may contribute to vascular remodelling events in the vein graft [48]. West et al [49] showed that Ad-nNOS gene transfer in a rabbit vein graft model favourably affected vein graft remodelling by inhibiting the early inflammatory changes and reducing late intimal hyperplasia [49]. They observed an increase in NOS activity, a reduction in adhesion molecule expression and inflammatory cell infiltration, and a reduction in basal superoxide generation.

Targeting SMC proliferation has also been shown to be effective using gene therapy protocols. In a rabbit model of vein grafting, Ad-mediated expression of a constitutively active form of the retinoblastoma gene product $(\mathrm{Ad} \Delta \mathrm{Rb})$ reduced neointima formation four weeks after surgery by $22 \%$ [50]. In the human saphenous vein model of vein graft, targeting SMC by overexpression of wild-type p53 both induced apoptosis and inhibited SMC migration resulting in a reduction in lesion formation [51]. Likewise, overexpression of C-type natriuretic peptide, which inhibits SMC growth by Ad resulted in accelerated graft re-endothelialisation and reduced thrombosis and neointima formation [52]. Kibbe et al [53] inhibited intimal hyperplasia in porcine vein grafts by incubation with Ad-iNOS for 30 minutes prior to surgery. This effect was sustained up to 21 days postgrafting [53]. While these strategies all show short-term effects, long-term studies are fundamentally important owing to the long-term nature of bypass graft failure.

\section{Thrombosis}

Defects in the vessel wall, namely, endothelial cell dysfunction can result in a reduction of antithrombotic activity leading to clot formation. The two main groups of anti-thrombotic genes are those with antiplatelet or anticoagulant activity. Prostacylin $\left(\mathrm{PGI}_{2}\right)$, nitric oxide (NO) and thrombin inhibitors all act through the inhibition of platelet adhesion and aggregation, in conjunction with the prevention of vascular SMC proliferation and vasoconstriction. The anti-thrombotic treatment, tissue plasminogen activator (tPA), which has anticoagulant properties and is used to lyse existing clots, may be a useful therapeutic gene for antithrombotic therapy (Table 1). The short half-life of tPA could be overcome with sustained overexpression from a gene therapy vector. Other anticoagulant gene products include hirudin, thrombomodulin, antistasin and, tissue factor pathway inhibitor
(TFPI). Hirudin is perhaps the most potent inhibitor of thrombin, the enzyme responsible for fibrinogen cleavage, platelet activation, and SMC proliferation [54]. The advantage of local expression of antithrombotic therapeutic genes is that not only is thrombolysis promoted at specific sites in the artery, but also the side effects of the conventional anticoagulant are avoided. Clinical conditions amenable to antithrombotic gene therapy include CABG, percutaneous transluminal coronary angioplasty, peripheral artery angioplasty, and intravascular stenting. Intravascular clot formation is a major cause of acute myocardial infarction and contributes to the majority of sudden deaths in patients with coronary artery disease. Successful thrombolysis for acute thrombosis is dependent on prompt treatment and delays in vector administration and expression of antithrombotic factors suggests that antithrombotic gene therapy is more likely to play a role in the prevention of reocclusion and chronic arterial narrowing. Cyclo-oxygenase-1 (COX-1), the rate limiting enzyme in the synthesis of $\mathrm{PGI}_{2}$, was overexpressed by local delivery of Ad to porcine carotid arteries immediately postangioplasty. This was shown to increase the levels of $\mathrm{PGI}_{2}$ and, in turn, inhibit thrombosis in injured vessels [55]. By manipulating the coagulation cascade integral in thrombus formation, a number of positive gene therapy studies have been reported. In a rabbit stasis/injury model of arterial thrombosis, local overexpression of thrombomodulin using Ad was assessed. In addition to reducing thrombosis, the vector did not induce inflammatory damage at the site of delivery [56]. Work by the same group targeting tissue-type plasminogen activator (tPA) also demonstrated effective prevention of thrombus formation [57]. Local gene transfer of TFPI into rabbit carotid arteries using an Ad vector prior to experimental thrombosis induction completely inhibited the formation of thrombi without affecting systemic coagulation status [58]. Similar data were described in the porcine carotid artery model following local delivery of Ad-TFPI [59].

\section{Atherosclerosis}

Due to the complexity and interplay of genetic and environmental factors in the development of atherosclerosis, it is unlikely that localized gene therapy will be a useful approach in the primary prevention of the disease. Inefficient intravascular gene transfer efficiency through atherosclerotic lesions and lipid-rich atheromas has been attributed to the very low numbers of transfectable cells and the high connective tissue content [60]. An extensive list of therapeutic genes exists for the treatment of atherosclerosis including LDL- or VLDL-receptor gene transfer to overcome LDL-receptor efficiency, a major inherited genetic defect and a determinant of atherosclerosis. Patients with defective enzymes vital for lipoprotein metabolism such as lipoprotein and hepatic lipases would benefit from gene transfer of DNA producing the correct enzymes. A reduction in the level of atherogenic 
apolipoprotein (apo) B100 is possible after gene transfer of the apoB mRNA editing enzyme, whilst lipoprotein A could be lowered with synthesis inhibiting ribozymes. Apolipoprotein AI (apoAI) and lecithin-cholesterol acyltransferase (LCAT) are important factors in the removal of excess cholesterol and the subsequent reduction in the incidence of atherosclerotic lesions (Table 1). Through in vitro bicistronic expression of these two genes from AAV plasmid vectors, it was shown that increased synthesis of apoAI and LCAT could play a role in reducing atherosclerotic risk [61].

The $\mathrm{apoE}^{-/-}$transgenic mouse is a well-established experimental model for atherosclerosis as it develops severe hypercholesterolaemia and atherosclerotic lesions similar to humans. Harris et al (2002) found that they could detect apoE mRNA in the muscle from a single intramuscular injection into the apoE $\mathrm{E}^{-/-}$mouse, but could not detect circulating recombinant apoE in the plasma [62]. However circulating antibodies were detected against the human apoE. The most significant finding of this study was three months after administration of the AAV-apoE they found a significant reduction (approximately 30\%) in atherosclerotic plague density in the aortas of treated animals compared to the controls. These results suggest that only low levels of apoE are required to produce protection against atherosclerosis.

Attenuation of lesion development has been demonstrated using Ad-mediated overexpression of heme oxygenase-1 [63], TIMP-1 [64], platelet-activating factor acetylhydrolase (PAF-AH) - the enzyme responsible for the inactivation of PAF [65] and apoE itself, administered intravenously [66]. Of particular significance, Kim et al [15] recently described the lifetime correction of hypercholesterolaemia in apoE $\mathrm{E}^{-/-}$mice following a single intravenous injection of a helper-dependent Ad vector. Followup of 2.5 years old mice demonstrated $100 \%$ coverage of the aorta with atherosclerotic plaques in control mice with almost no lesion development in treated animals [15].

\section{Hypertension}

Systemic hypertension is a common multifactorial disorder primarily manifesting itself as chronic high blood pressure and is a major risk factor for atherosclerosis, peripheral vascular disease stroke, and many other complications associated with structural damage to the cardiovascular system. Drugs for controlling high blood pressure are effective over a 24-hour period, are nonspecific and cause side effects. It is well established that the hyperactive renin-angiotensin system (RAS) is a key factor in primary hypertension and gene therapy strategies have concentrated on those genes in the RAS controlling regulation of blood pressure.

Due to its multifactorial nature, gene therapy for hypertension has yet to be demonstrated clinically. Many gene therapy interventions have, however, been employed successfully in the laboratory (for review, see $[67,68,69]$ ). Targeting elements involved in the oxidative stress path- ways (Table 1), Alexander et al [70] and Fennell et al [71] have demonstrated an improvement of endothelial function in the SHRSP with local delivery of Ad-eNOS [70] or Ad-extracellular SOD [71]. Angiotensin II-induced hypertension and accompanying endothelial dysfunction were studied by Nakane et al [72]. Gene transfer of AdeNOS but not SOD (copper/zinc or extracellular SOD) was shown to restore endothelial function ex vivo in aortic rings from treated rabbits [72]. Ad-eNOS delivery into the rostral ventrolateral medulla of SHRSP and WKY rats resulted in a significant reduction in blood pressure in both rats [73]. A continuous supply of tissue kallikrein by a single intramuscular injection of Ad produced a significant delay of elevated blood pressure for five weeks in the SHR [74]. An increase in vasodilator proteins such as kallikrein, eNOS, and atrial natriuretic peptide (ANP) in animal models has correlated with a reduction in blood pressure [75].

Antisense targeting angiotensinogen and the angiotensin type-1 (AT1) receptor attempted to decrease those genes responsible for vasoconstriction [76]. AAVplasmids have been used to deliver antisense AT1-R to SHR rats [76]. They showed that a single intracardiac injection was sufficient to reduce blood pressure by $30 \mathrm{~mm}$ $\mathrm{Hg}$ when compared to the controls over a five-week period [76]. The effect of AAV-AGT-AS on the development of hypertension in SHR rats has also been examined. The rats were injected with AAV-AGT-AS five days after birth as the development of hypertension in SHR rats commences between the eighth and tenth week after birth. A significant slowing of the development of hypertension for six months was observed but there was no complete inhibition of the rise in blood pressure [77].

\section{THE FUTURE OF GENE THERAPY IN THE TREATMENT OF CARDIOVASCULAR DISEASE}

Due to the complexity of cardiovascular disorders, a major stumbling block may be the identification of the best gene to treat the disease. It is most likely that a cocktail of therapeutic genes rather than a single particular gene will be the most effective treatment of certain cardiovascular diseases such as hypertension and atherosclerosis. In order for gene therapy to become a reality in the cardiovascular clinic, effective therapeutic genes and suitable vectors must be identified and developed. Results from the first clinical trials have indicated that vascular gene transfer is not only safe but may have therapeutic benefits when administered intravascularly or intramuscularly.

\section{REFERENCES}

[1] Isner JM, Vale PR, Symes JF, Losordo DW. Assessment of risks associated with cardiovascular gene therapy in human subjects. Circ Res. 2001;89(5): 389-400. 
[2] Kingston PA, Sinha S, David A, Castro MG, Lowenstein PR, Heagerty AM. Adenovirus-mediated gene transfer of a secreted transforming growth factor- $\beta$ type II receptor inhibits luminal loss and constrictive remodeling after coronary angioplasty and enhances adventitial collagen deposition. Circulation. 2001;104(21):2595-2601.

[3] Baker AH, Mehta D, George SJ, Angelini GD. Prevention of vein graft failure: potential applications for gene therapy. Cardiovasc Res. 1997;35(3):442450.

[4] Grossman M, Rader DJ, Muller D, et al. A pilot study of ex vivo gene therapy for homozygous familial hypercholesterolaemia. Nat Med. 1995;1(11):11481154.

[5] Forough R, Koyama N, Hasenstab D, et al. Overexpression of tissue inhibitor of matrix metalloproteinase- 1 inhibits vascular smooth muscle cell functions in vitro and in vivo. Circ Res. 1996;79(4):812820.

[6] Nabel EG, Plautz G, Nabel GJ. Site-specific gene expression in vivo by direct gene transfer into the arterial wall. Science. 1990;249(4974):1285-1288.

[7] Yang X, Atalar E, Li D, et al. Magnetic resonance imaging permits in vivo monitoring of catheterbased vascular gene delivery. Circulation. 2001; 104(14):1588-1590.

[8] Klugherz BD, Jones PL, Cui X, et al. Gene delivery from a DNA controlled-release stent in porcine coronary arteries. Nat Biotechnol. 2000;18(11):11811184 .

[9] Baim DS, Wahr D, George B, et al. Randomized trial of a distal embolic protection device during percutaneous intervention of saphenous vein aortocoronary bypass grafts. Circulation. 2002;105(11): 1285-1290.

[10] Panetta CJ, Miyauchi K, Berry D, et al. A tissueengineered stent for cell-based vascular gene transfer. Hum Gene Ther. 2002;13(3):433-441.

[11] Vassalli G, Dichek DA. Gene therapy for arterial thrombosis. Cardiovasc Res. 1997;35(3):459-469.

[12] Yla-Herttuala S, Martin JF. Cardiovascular gene therapy. Lancet. 2000;355(9199):213-222.

[13] Jaffe HA, Danel C, Longenecker G, et al. Adenovirusmediated in vivo gene transfer and expression in normal rat liver. Nat Genet. 1992;1(5):372-378.

[14] Koeberl DD, Alexander IE, Halbert CL, Russell DW, Miller AD. Persistent expression of human clotting factor IX from mouse liver after intravenous injection of adeno-associated virus vectors. Proc Natl Acad Sci USA. 1997;94(4):1426-1431.

[15] Kim IH, Jozkowicz A, Piedra PA, Oka K, Chan L. Lifetime correction of genetic deficiency in mice with a single injection of helper-dependent adenoviral vector. Proc Natl Acad Sci USA. 2001;98(23): 13282-13287.

[16] Ponder KP. Systemic gene therapy for cardiovascular disease. Trends Cardiovasc Med. 1999;9(6):158-162.
[17] Flotte TR, Afione SA, Zeitlin PL. Adeno-associated virus vector gene expression occurs in nondividing cells in the absence of vector DNA integration. Am J Respir Cell Mol Biol. 1994;11(5):517-521.

[18] Kotin RM, Siniscalco M, Samulski RJ, et al. Sitespecific integration by adeno-associated virus. Proc Natl Acad Sci USA. 1990;87(6):2211-2215.

[19] Young SM Jr, McCarty DM, Degtyareva N, Samulski RJ. Roles of adeno-associated virus Rep protein and human chromosome 19 in site-specific recombination. J Virol. 2000;74(9):3953-3966.

[20] Rinaudo D, Lamartina S, Roscilli G, Ciliberto G, Toniatti C. Conditional site-specific integration into human chromosome 19 by using a ligand-dependent chimeric adeno-associated virus/Rep protein. J Virol. 2000;74(1):281-294.

[21] Xiao X, Li J, Samulski RJ. Efficient long-term gene transfer into muscle tissue of immunocompetent mice by adeno-associated virus vector. J Virol. 1996; 70(11):8098-8108.

[22] Phillips MI, Wielbo D, Gyurko R. Antisense inhibition of hypertension: a new strategy for reninangiotensin candidate genes. Kidney Int. 1994;46(6): 1554-1556.

[23] Morishita R, Aoki M, Kaneda Y. Oligonucleotidebased gene therapy for cardiovascular disease: are oligonucleotide therapeutics novel cardiovascular drugs? Curr Drug Targets. 2000;1(1):15-23.

[24] Taniyama Y, Univ O, Jsapan S, et al. Local delivery of naked plasmid DNA of p53 gene into rat balloon injured carotid artery using low voltage ultrasound with contrast microbubbles (optison): development of novel non-viral transfection system into blood vessels. Circulation. 2000;102(suppl II):II-164 abstract.

[25] Asahara T, Chen D, Tsurumi Y, et al. Accelerated restitution of endothelial integrity and endotheliumdependent function after phVEGF ${ }_{165}$ gene transfer. Circulation. 1996;94(12):3291-3302.

[26] Tsurumi Y, Takeshita S, Chen D, et al. Direct intramuscular gene transfer of naked DNA encoding vascular endothelial growth factor augments collateral development and tissue perfusion. Circulation. 1996;94(12):3281-3290.

[27] Losordo DW, Vale PR, Symes JF, et al. Gene therapy for myocardial angiogenesis: initial clinical results with direct myocardial injection of phVEGF 165 as sole therapy for myocardial ischemia. Circulation. 1998;98(25):2800-2804.

[28] Baumgartner I, Pieczek A, Manor O, et al. Constitutive expression of phVEGF ${ }_{165}$ after intramuscular gene transfer promotes collateral vessel development in patients with critical limb ischemia. Circulation. 1998;97(12):1114-1123.

[29] Gowdak LH, Poliakova L, Wang X, et al. Adenovirusmediated $\mathrm{VEGF}_{121}$ gene transfer stimulates angiogenesis in normoperfused skeletal muscle and preserves tissue perfusion after induction of ischemia. Circulation. 2000;102(5):565-571. 
[30] Rajagopalan S, Shah M, Luciano A, Crystal R, Nabel EG. Adenovirus-mediated gene transfer of $\mathrm{VEGF}_{121}$ improves lower-extremity endothelial function and flow reserve. Circulation. 2001;104(7):753755.

[31] Rosengart TK, Lee LY, Patel SR, et al. Angiogenesis gene therapy: phase I assessment of direct intramyocardial administration of an adenovirus vector expressing $\mathrm{VEGF}_{121} \mathrm{cDNA}$ to individuals with clinically significant severe coronary artery disease. Circulation. 1999;100(5):468-474.

[32] Grines CL, Watkins MW, Helmer G, et al. Angiogenic Gene Therapy (AGENT) trial in patients with stable angina pectoris. Circulation. 2002;105(11): 1291-1297.

[33] Shimpo M, Ikeda U, Maeda Y, et al. AAV-mediated VEGF gene transfer into skeletal muscle stimulates angiogenesis and improves blood flow in a rat hindlimb ischemia model. Cardiovasc Res. 2002; 53(4):993-1001.

[34] Su H, Lu R, Kan YW. Adeno-associated viral vectormediated vascular endothelial growth factor gene transfer induces neovascular formation in ischemic heart. Proc Natl Acad Sci USA. 2000;97(25):1380113806.

[35] Celletti FL, Waugh JM, Amabile PG, Brendolan A, Hilfiker PR, Dake MD. Vascular endothelial growth factor enhances atherosclerotic plaque progression. Nat Med. 2001;7(4):425-429.

[36] Springer ML, Chen AS, Kraft PE, Bednarski M, Blau HM. VEGF gene delivery to muscle: potential role for vasculogenesis in adults. Mol Cell. 1998;2(5): 549-558.

[37] Lee RJ, Springer ML, Blanco-Bose WE, Shaw R, Ursell PC, Blau HM. VEGF gene delivery to myocardium: deleterious effects of unregulated expression. Circulation. 2000;102(8):898-901.

[38] Melo LG, Agrawal R, Zhang L, et al. Gene therapy strategy for long-term myocardial protection using adeno-associated virus-mediated delivery of heme oxygenase gene. Circulation. 2002;105(5):602607.

[39] Phillips MI, Tang Y, Schmidt-Ott K, Qian K, Kagiyama S. Vigilant vector: heart-specific promoter in an adeno-associated virus vector for cardioprotection. Hypertension. 2002;39(pt 2):651-655.

[40] Wheeler MD, Katuna M, Smutney OM, et al. Comparison of the effect of adenoviral delivery of three superoxide dismutase genes against hepatic ischemia-reperfusion injury. Hum Gene Ther. 2001; 12(18):2167-2177.

[41] Kibbe MR, Billiar TR, Tzeng E. Gene therapy for restenosis. Circ Res. 2000;86(8):829-833.

[42] Mann MJ, Whittemore AD, Donaldson MC, et al. Ex-vivo gene therapy of human vascular bypass grafts with E2F decoy: the PREVENT singlecentre, randomised, controlled trial. Lancet. 1999; 354(9189):1493-1498.
[43] Hu Y, Baker AH, Zou Y, Newby AC, Xu Q. Local gene transfer of tissue inhibitor of metalloproteinase-2 influences vein graft remodeling in a mouse model. Arterioscler Thromb Vasc Biol. 2001;21(8):12751280.

[44] Baker AH, Zaltsman AB, George SJ, Newby AC. Divergent effects of tissue inhibitor of metalloproteinase-1, -2, or -3 overexpression on rat vascular smooth muscle cell invasion, proliferation, and death in vitro. TIMP-3 promotes apoptosis. J Clin Invest. 1998;101(6):1478-1487.

[45] Bond M, Murphy G, Bennett MR, Newby AC, Baker AH. Tissue inhibitor of metalloproteinase- 3 induces a Fas-associated death domain-dependent type II apoptotic pathway. J Biol Chem. 2002;277(16): 13787-13795.

[46] George SJ, Lloyd CT, Angelini GD, Newby AC, Baker $\mathrm{AH}$. Inhibition of late vein graft neointima formation in human and porcine models by adenovirusmediated overexpression of tissue inhibitor of metalloproteinase-3. Circulation. 2000;101(3):296304.

[47] George SJ, Johnson JL, Angelini GD, Newby AC, Baker AH. Adenovirus-mediated gene transfer of the human TIMP-1 gene inhibits smooth muscle cell migration and neointimal formation in human saphenous vein. Hum Gene Ther. 1998;9(6):867877.

[48] Buttery LD, Chester AH, Springall DR, et al. Explanted vein grafts with an intact endothelium demonstrate reduced focal expression of endothelial nitric oxide synthase specific to atherosclerotic sites. J Pathol. 1996;179(2):197-203.

[49] West NE, Qian H, Guzik JJ, et al. Nitric oxide synthase (nNOS) gene transfer modifies venous bypass graft remodeling: effects on vascular smooth muscle cell differentiation and superoxide production. Circulation. 2001;104(13):1526-1532.

[50] Schwartz LB, Moawad J, Svensson EC, et al. Adenoviral-mediated gene transfer of a constitutively active form of the retinoblastoma gene product attenuates neointimal thickening in experimental vein grafts. J Vasc Surg. 1999;29(5):874-881.

[51] George SJ, Angelini GD, Capogrossi MC, Baker AH. Wild-type p53 gene transfer inhibits neointima formation in human saphenous vein by modulation of smooth muscle cell migration and induction of apoptosis. Gene Ther. 2001;8(9):668-676.

[52] Ohno N, Itoh H, Ikeda T, Ueyama K, et al. Accelerated reendothelialization with suppressed thrombogenic property and neointimal hyperplasia of rabbit jugular vein grafts by adenovirus-mediated gene transfer of C-type natriuretic peptide. Circulation. 2002;105(14):1623-1626.

[53] Kibbe MR, Tzeng E, Gleixner SL, et al. Adenovirusmediated gene transfer of human inducible nitric oxide synthase in porcine vein grafts inhibits intimal hyperplasia. J Vasc Surg. 2001;34(1):156-165. 
[54] Mehta SR, Eikelboom JW, Rupprecht HJ, et al. Efficacy of hirudin in reducing cardiovascular events in patients with acute coronary syndrome undergoing early percutaneous coronary intervention. Eur Heart J. 2002;23(2):117-123.

[55] Zoldhelyi P, McNatt J, Xu XM, et al. Prevention of arterial thrombosis by adenovirus-mediated transfer of cyclooxygenase gene. Circulation. 1996;93(1):1017.

[56] Waugh JM, Yuksel E, Li J, et al. Local overexpression of thrombomodulin for in vivo prevention of arterial thrombosis in a rabbit model. Circ Res. 1999;84(1):84-92.

[57] Waugh JM, Kattash M, Li J, et al. Gene therapy to promote thromboresistance: local overexpression of tissue plasminogen activator to prevent arterial thrombosis in an in vivo rabbit model. Proc Natl Acad Sci USA. 1999;96(3):1065-1070.

[58] Nishida T, Ueno H, Atsuchi N, et al. Adenovirusmediated local expression of human tissue factor pathway inhibitor eliminates shear stress-induced recurrent thrombosis in the injured carotid artery of the rabbit. Circ Res. 1999;84(12):1446-1452.

[59] Zoldhelyi P, McNatt J, Shelat HS, Yamamoto Y, Chen ZQ, Willerson JT. Thromboresistance of ballooninjured porcine carotid arteries after local gene transfer of human tissue factor pathway inhibitor. Circulation. 2000;101(3):289-295.

[60] Laitinen M, Makinen K, Manninen $H$, et al. Adenovirus-mediated gene transfer to lower limb artery of patients with chronic critical leg ischemia. Hum Gene Ther. 1998;9(10):1481-1486.

[61] Fan L, Drew J, Dunckley MG, Owen JS, Dickson G. Efficient coexpression and secretion of antiatherogenic human apolipoprotein AI and lecithincholesterol acyltransferase by cultured muscle cells using adeno-associated virus plasmid vectors. Gene Ther. 1998;5(10):1434-1440.

[62] Harris JD, Schepelmann S, Athanasopoulos T, et al. Inhibition of atherosclerosis in apolipoprotein-Edeficient mice following muscle transduction with adeno-associated virus vectors encoding human apolipoprotein-E. Gene Ther. 2002;9(1):21-29.

[63] Juan SH, Lee TS, Tseng KW, et al. Adenovirusmediated heme oxygenase-1 gene transfer inhibits the development of atherosclerosis in apolipoprotein E-deficient mice. Circulation. 2001;104(13):15191525.

[64] Rouis M, Adamy C, Duverger N, et al. Adenovirusmediated overexpression of tissue inhibitor of metalloproteinase-1 reduces atherosclerotic lesions in apolipoprotein E-deficient mice. Circulation. 1999;100(5):533-540.

[65] Quarck R, De Geest B, Stengel D, et al. Adenovirusmediated gene transfer of human platelet-activating factor-acetylhydrolase prevents injury-induced neointima formation and reduces spontaneous ath- erosclerosis in apolipoprotein E-deficient mice. Circulation. 2001;103(20):2495-2500.

[66] Harris JD, Graham IR, Schepelmann S, et al. Acute regression of advanced and retardation of early aortic atheroma in immunocompetent apolipoprotein$\mathrm{E}$ (apoE) deficient mice by administration of a second generation [E1(-), E3(-), polymerase(-)] adenovirus vector expressing human apoE. Hum Mol Genet. 2002;11(1):43-58.

[67] Phillips MI. Is gene therapy for hypertension possible? Hypertension. 1999;33(1):8-13.

[68] Phillips MI. Gene therapy for hypertension: the preclinical data. Methods Enzymol. 2002;346:3-13.

[69] Gelband CH, Katovich MJ, Raizada MK. Current perspectives on the use of gene therapy for hypertension. Circ Res. 2000;87(12):1118-1122.

[70] Alexander MY, Brosnan MJ, Hamilton CA, et al. Gene transfer of endothelial nitric oxide synthase but not $\mathrm{Cu} / \mathrm{Zn}$ superoxide dismutase restores nitric oxide availability in the SHRSP. Cardiovasc Res. 2000;47(3):609-617.

[71] Fennell JP, Brosnan MJ, Frater AJ, et al. Adenovirusmediated overexpression of extracellular superoxide dismutase improves endothelial dysfunction in a rat model of hypertension. Gene Ther. 2002;9(2):110117.

[72] Nakane H, Miller FJ Jr, Faraci FM, Toyoda K, Heistad DD. Gene transfer of endothelial nitric oxide synthase reduces angiotensin II-induced endothelial dysfunction. Hypertension. 2000;35(2):595-601.

[73] Kishi T, Hirooka Y, Ito K, Sakai K, Shimokawa H, Takeshita A. Cardiovascular effects of overexpression of endothelial nitric oxide synthase in the rostral ventrolateral medulla in stroke-prone spontaneously hypertensive rats. Hypertension. 2002;39(2):264268.

[74] Zhang JJ, Wang C, Lin KF, Chao L, Chao J. Human tissue kallikrein attenuates hypertension and secretes into circulation and urine after intramuscular gene delivery in hypertensive rats. Clin Exp Hypertens. 1999;21(7):1145-1160.

[75] Chao J, Chao L. Kallikrein gene therapy: a new strategy for hypertensive diseases. Immunopharmacology. 1997;36(2-3):229-236.

[76] Phillips MI, Mohuczy-Dominiak D, Coffey M, et al. Prolonged reduction of high blood pressure with an in vivo, nonpathogenic, adeno-associated viral vector delivery of AT1-R mRNA antisense. Hypertension. 1997;29(1 Pt 2):374-380.

[77] Kimura B, Mohuczy D, Tang X, Phillips MI. Attenuation of hypertension and heart hypertrophy by adeno-associated virus delivering angiotensinogen antisense. Hypertension. 2001;37(pt 2):376-380.

* Corresponding author.

E-mail: ab11f@clinmed.gla.ac.uk

Fax: +44 1412111763; Tel: +44 1412112100 

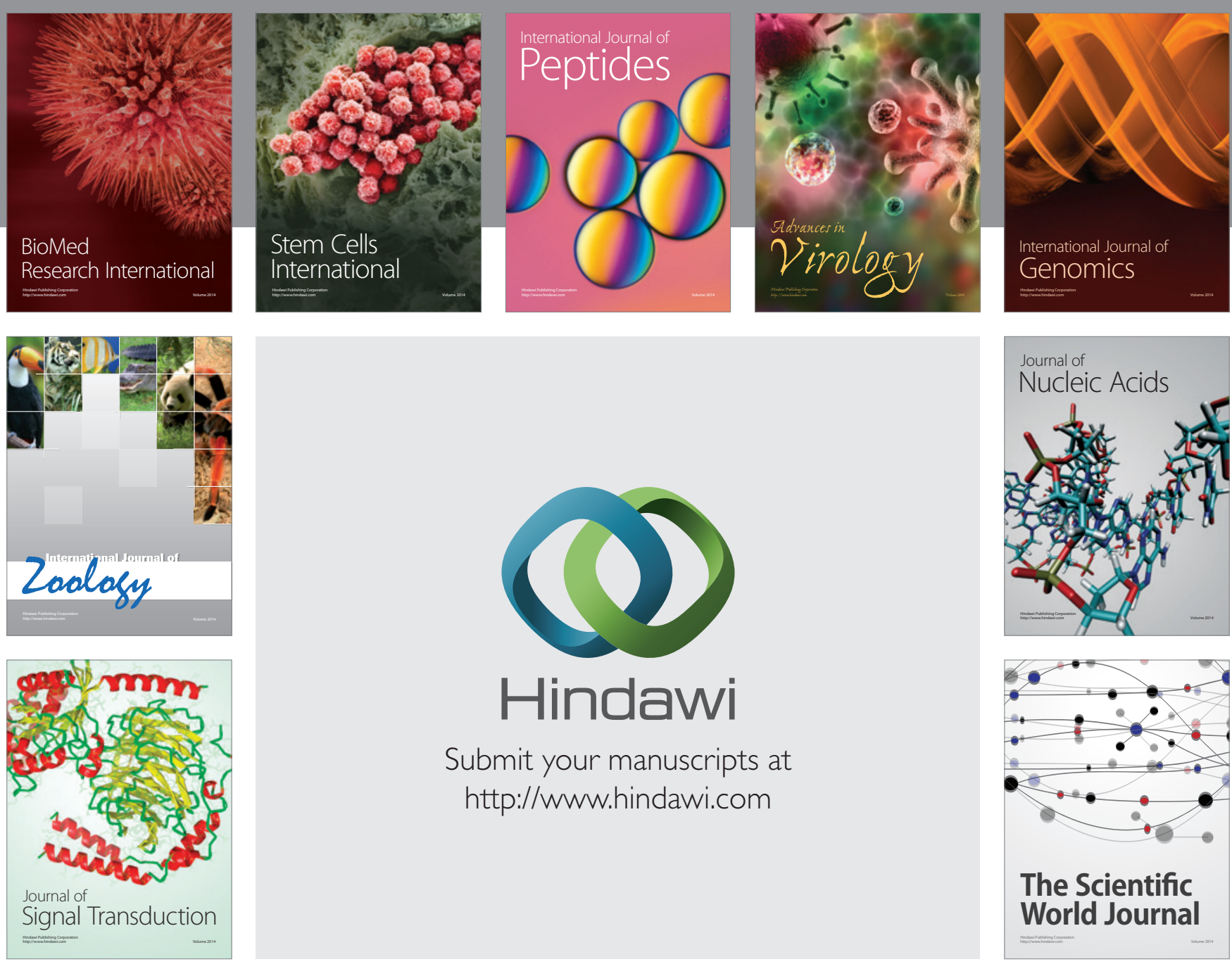

Submit your manuscripts at

http://www.hindawi.com
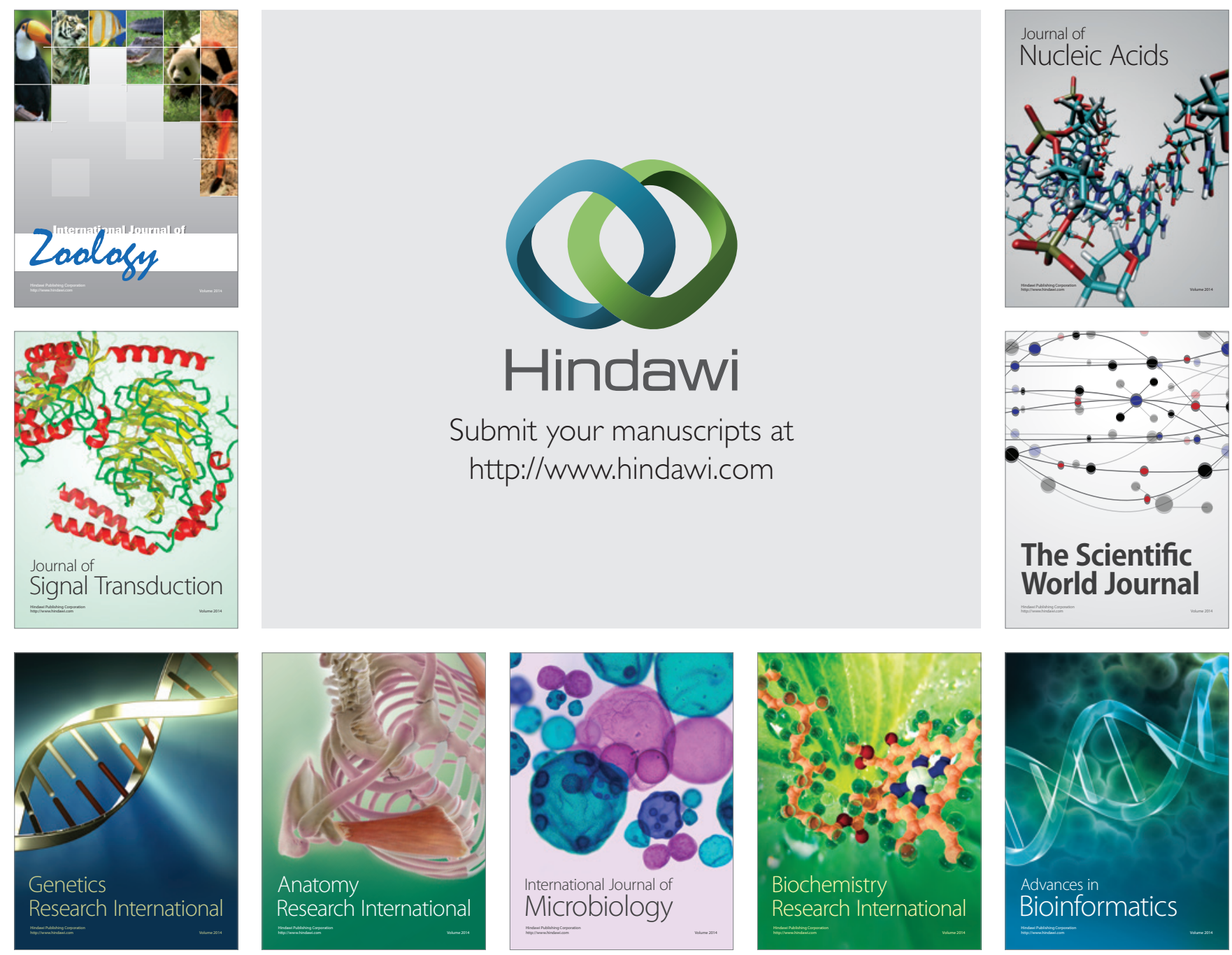

The Scientific World Journal
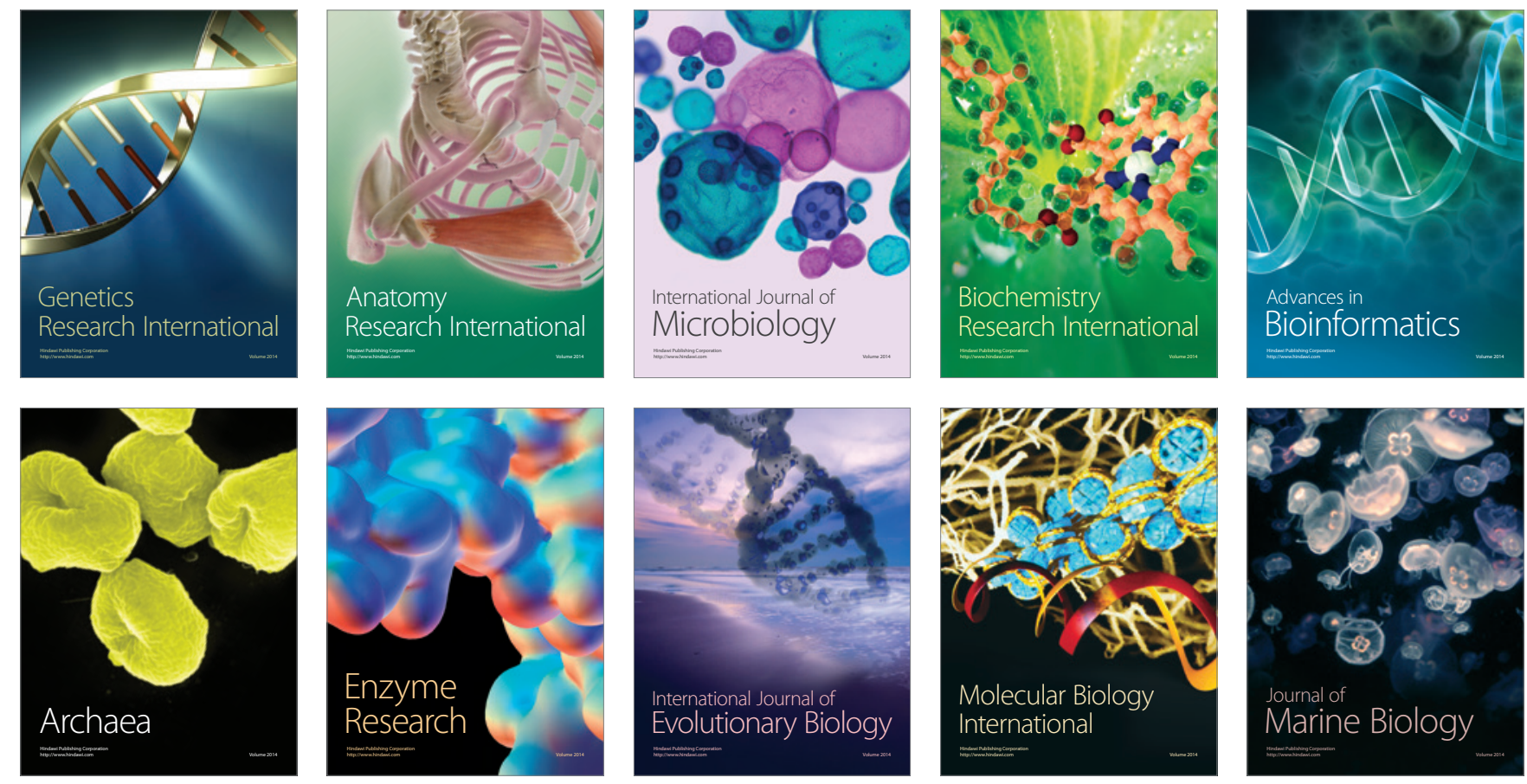